\title{
Continuity of care policy exposes fault lines in the medical profession
}

\author{
— Cite as: CMAJ 2020 January 20;192:E75-6. doi: 10.1503/cmaj.1095836
}

Posted on cmajnews.com on December 19, 2019

ome specialists and family doctors in Ontario are locked in a standoff over who should take responsibility for contacting patients about appointments.

Last fall, the College of Physicians and Surgeons of Ontario (CPSO) released a suite of policies on continuity of care that set new expectations for doctors around availability and coverage, managing tests, transitions in care, and walk-in clinics.

Medical regulators in other provinces have set similar policies in recent years, spurred by the death of an Alberta man in 2012 following multiple failures in care. "We were one of the only jurisdictions that had not really yet waded into this territory," says Craig Roxborough, manager of policy at the CPSO.

The policies are sparking controversy, particularly the new policy on transitions in care, which includes an obligation for consulting physicians to contact patients directly about appointments. Previously, the task often fell to the referring physician.

During consultations on the policy, specialists argued that referring doctors should be responsible for communicating with patients until they see a specialist. But referring physicians complained that relaying messages between patients and specialists wastes time and money, and patients can get lost in the shuffle.

Dr. Adam Stewart, a family doctor in Madoc, Ont., is one of many referring physicians who welcomed the new rules. In 2017, Stewart called on the Ontario Medical Association (OMA) to clarify who was responsible for communicating with patients after his

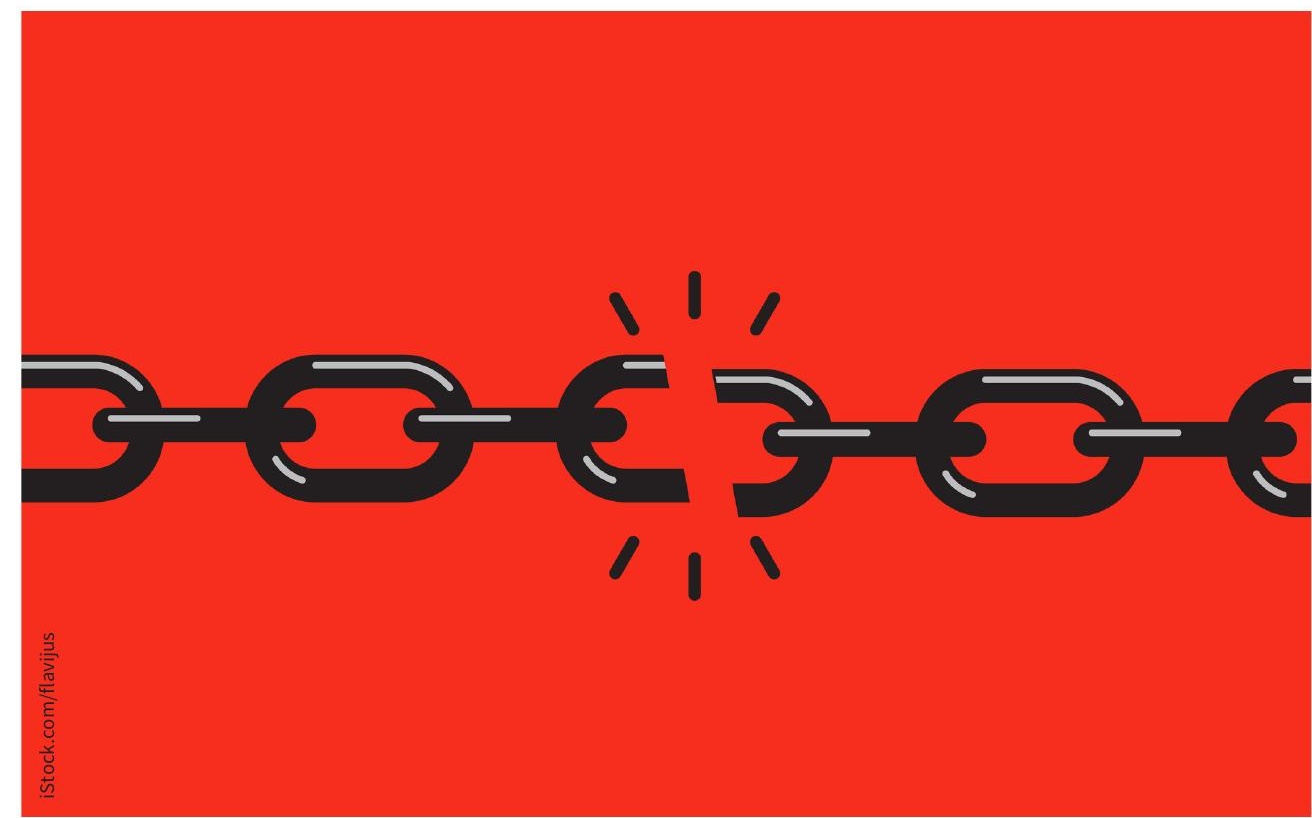

Referrals remain a point of contention between specialists and referring physicians despite new guidance.

attempts to resolve the problem with local physicians failed. "It's always puzzled me why general practitioners are doing administrative work on behalf of specialists," Stewart says, noting that he employed a full-time staff member to deal with referrals.

But as Stewart implemented the new policy, he faced resistance from consulting physicians. "My staff took a lot of anger," he says.

Such resistance raises concerns about the culture of medicine, says Dr. Lesley Barron, a general surgeon in Georgetown, Ont. "Culture eats policy for breakfast," Barron says, and up to now, there was a culture of offloading administrative tasks. "There are already comments on social media about this policy not being followed," she says. "It speaks poorly of us as a profession when the college needs to get involved in these sorts of things."

There are other concerns, too. The policies are unclear on referrals to diagnostic imaging and some facilities still require the referring physician to contact the patient. Roxborough says different policies apply depending on how the imaging is arranged. The ordering physician is responsible for follow-up if they give the requisition to the patient, but if the physician sends the requisition to the facility, the facility is responsible for follow-up.

The College of Physicians and Surgeons of Alberta faced resistance implementing a similar policy in 2017. "We basically laid it 
out very clearly in bold print, 27 [point] font, flashing lights and disco balls because frankly it wasn't being paid attention," says Dr. Michael Caffaro, assistant registrar of the college.

In British Columbia, specialists who fail to contact patients with the date and time of appointments face remediation. Some have reportedly told referring physicians that they regard guidelines on the issue as "optional."

Understaffing may also contribute to the problem. According to the College of Physicians and Surgeons of British Columbia, the small number of specialists who reportedly refuse to contact patients directly tend to see high volumes of referrals. In one case, a specialist's office facing complaints for failing to answer or initiate calls was "simply short-staffed." Once the specialist hired a part-time assistant to return calls, the complaints stopped.
In Ontario, the CPSO and OMA are fielding concerns about the new suite of policies on continuity of care. According to OMA President Dr. Sohail Gandhi, the association is also providing templates that members can use as a "gentle reminder" to colleagues.

The response to the suite of policies has been mixed. Early drafts set strong mandates for availability, including requirements that doctor's offices accept after-hours voicemail messages and have a plan for coordinating care outside of operating hours. But CPSO dropped these and other mandates from the final policies following pushback from the OMA.

According to Gandhi, the draft policy "did not account for the fact that our health care infrastructure isn't able to meet some of these needs." But some physicians argue the compromise leaves major gaps in care.
Meanwhile, there is a push for definitive solutions to the infrastructure issues at the root of breakdowns in care. "The biggest problem here is that communication is taking place using 20th century technology - fax machines, phones," says Dr. Jonathan Marcus, a family physician in Toronto. He supports connecting the province's various electronic medical records to a common database. According to Barron, centralizing referrals would also improve care.

Dr. Hasan Habib, a family physician in Waterloo, says the OMA should negotiate with the province for funding for better infrastructure. The focus should be on advocating for solutions as a group, he says. "It's not about [family doctor] versus specialist. The issue should unite us to find a common solution."

Dr. Tola Overduin, Waterloo, Ont. 